\title{
PREVALENCE OF ATYPICAL BACTERIAL PNEUMONIA IN PATIENTS PRESENTING WITH LOWER RESPIRATORY TRACT INFECTIONS AT A TERTIARY CARE CENTRE
}

\author{
K. Ramesh Kumar1, G. Sowjanya², P. Shashikala Reddy3 \\ ${ }^{1}$ Associate Professor of T.B. and Respiratory Diseases, Department of T.B. and Chest Medicine, Government General and Chest Hospital, \\ Osmania Medical College, Hyderabad. \\ ${ }^{2}$ Postgraduate Student, Department of Microbiology, Government General and Chest Hospital, Osmania Medical College, Hyderabad. \\ 3Professor, Department of Microbiology, Government General and Chest Hospital, Osmania Medical College, Hyderabad.
}

\section{ABSTRACT}

\section{BACKGROUND}

A number of different viral, bacterial, fungal and protozoan organisms can cause atypical pneumonia; the three most common are Chlamydia pneumoniae, Legionella pneumophila, and Mycoplasma pneumoniae. Atypical pneumonias are by far the most underdiagnosed and underreported clinical entities, and very few studies have been reported in India. This study was conducted from March 2015 to September 2015 to determine the seroprevalence of M. pneumoniae, Chlamydia pneumoniae and Legionella pneumophila antibodies in patients with lower respiratory tract infections, and to compare IgM ELISA with that of the Sanger sequencing. Sequencing proved to be one of the rapid, sensitive and specific method of diagnosis in these cases.

\section{MATERIALS AND METHODS}

This cross sectional hospital based study was done at Government General and Chest Hospital, Erragadda, Hyderabad. The study population included 90 patients attending outpatient department and admitted as inpatients between March 2015 to September 2015 with a high probability of atypical pneumonia based on clinical symptoms and signs like fever, cough, dyspnoea, headache. Crepitations and presence of new pulmonary infiltrates on chest x-ray, in cases like COPD with acute exacerbation, bronchial asthma with acute exacerbation and Community-acquired pneumonia cases. Sputum and serum samples collected from each patient. 90 blood samples collected were subjected to ELISA to detect IgM antibody (EUROIMMUN) for Chlamydia pneumoniae, Legionella pneumophila, and Mycoplasma pneumoniae. The sputum samples showing no pathogenic organisms (NPO) were subjected to PCR for amplification of V3 region of 16 SMA followed by Sanger sequencing.

\section{RESULTS}

17 cases were positive for IgM antibodies for atypical bacteria and 8 cases were positive by Sanger sequencing. The common presenting symptoms were cough, fever, chest pain, dyspnoea and headache. More number of cases were detected in Communityacquired pneumonia patients followed by COPD and bronchial asthma with acute exacerbation.

\section{CONCLUSION}

IgM ELISA having correlated clinically with reasonable sensitivity could be a useful tool in diagnosing atypical pneumonia caused by L. pneumophila, M. pneumoniae and C pneumoniae. Sanger sequencing in comparisons of low sensitivity although highly specific can be recommended for application in discriminating species and not for diagnosis from sputum samples.

\section{KEYWORDS}

Atypical Bacteria, Sanger Sequence, ELISA.

HOW TO CITE THIS ARTICLE: Kumar KR, Sowjanya G, Reddy PS. Prevalence of atypical bacterial pneumonia in patients presenting with lower respiratory tract infections at a tertiary care centre. J. Evolution Med. Dent. Sci. 2017;6(20):1589-1594, DOI: $10.14260 /$ Jemds/2017/349

\section{BACKGROUND}

Community-acquired pneumonias (CAP) are caused by an infection with Streptococcus pneumonia. In 30 to 40 percent of cases, so-called "atypical pathogens" are responsible for the disease. ${ }^{1}$ Although a number of different viral, bacterial, fungal and protozoan organisms can cause atypical pneumonia, the three most common are Chlamydia pneumoniae, Legionella pneumophila, and Mycoplasma pneumoniae. $^{2}$

Financial or Other, Competing Interest: None.

Submission 23-01-2017, Peer Review 16-02-2017,

Acceptance 22-02-2017, Published 09-03-2017.

Corresponding Author:

Dr. K. Ramesh Kumar

\#39, SRT Ameerpet,

Hyderabad-500016.

E-mail: drrameshkumar2007@gmail.com

DOI: $10.14260 /$ jemds $/ 2017 / 349$

Mycoplasma pneumoniae are a common cause of community-acquired, respiratory tract infections, especially in children and young adults. Approximately, $10 \%$ of the cases of CAP that occur endemically, and up to $50 \%$ of the cases that occur in epidemic periods are caused by $\mathrm{M}$. pneumoniae ${ }^{3}$ groups. Pneumonia due to M. pneumoniae is typically characterised by a violent and dry cough producing only sparse whitish mucus. Other symptoms include headache, malaise and sore throat. ${ }^{4}$ Legionnaires' pneumonia is caused by Legionella species which are responsible for 2$55 \%$ of CAP. ${ }^{5}$ Legionella pneumophila (92\%) is the most common cause of Legionnaires' disease. Majority of clinical strains are serogroup1 isolates of L. Pneumophila. ${ }^{6}$ Chlamydophila pneumoniae, common cause of communityacquired respiratory infections, including bronchitis and upper respiratory tract infections, are responsible for 6-20\% of all community-acquired pneumonias. ${ }^{7}$ 
The atypical pathogens do not respond to $\beta$-lactam antimicrobial therapy. Therefore, appropriate treatment of CAP requires the identification of the infecting pathogens ${ }^{8}$ with rapid and sensitive diagnostic test which is essential not only for treatment but also for the implementation of preventive measures ${ }^{9}$ as CAP are clinically not distinguishable from other pneumonias. Timely and appropriate treatment improves the prognosis and can be achieved by rapid diagnosis. ${ }^{10}$ Thus, for better management a laboratory diagnosis is important to detect or to rule out $\mathrm{M}$. pneumoniae infection from other respiratory infection. ${ }^{11}$

Atypical pneumonias are by far the most underdiagnosed and underreported clinical entities, and very few studies have been reported in India. This study was conducted to determine the seroprevalence of M. pneumoniae, Chlamydia pneumoniae and Legionella pneumophila antibodies in patients with lower respiratory tract infections and to compare IgM ELISA with that of the Sanger sequencing.

\section{Aims and Objectives}

- To study the prevalence of infection with Mycoplasma pneumoniae, Chlamydia pneumoniae, Legionella species in patients presenting with signs and symptoms of lower respiratory tract infection.

- To diagnose atypical pneumonia with $\operatorname{lgM}$ ELISA $\{\mathrm{L}$. pneumophila, M. pneumoniae, C. pneumoniae $\}$ of serum samples.

- $\quad$ To subject sputum samples to Sanger sequencing and to compare sensitivity of the two methods.

- To evaluate use of these two methods in support of clinicoradiological diagnosis in diagnosis and timely treatment of cases of atypical pneumonia.

\section{MATERIALS AND METHODS}

The study was conducted during the period March 2015 to September 2015. The study group consisted of 90 patients attending medical outpatient department and admitted in Government General and Chest Hospital, Erragadda, Hyderabad.

\section{Inclusion Criteria}

- Patients with Community-acquired pneumonia.

- Acute exacerbation of bronchial asthma.

- Chronic Obstructive Pulmonary Disease.

- $\quad$ Age 16 to 65 years.

- Patients presenting with symptoms and signs of fever, cough, dyspnoea and headache, presence of new pulmonary infiltrates and features of interstitial consolidation on chest $\mathrm{x}$-ray.

- All patients were admitted in medical wards during the period of evaluation.

\section{Exclusion Criteria}

- Hospital-acquired pneumonia.

- Bronchiectasis.

- Interstitial lung disease.

- Pulmonary tuberculosis.

- Age $<16$ years and $>65$ years.

- ICU patients and patients with cardiac symptoms.
Sputum and serum samples were collected from patients with a high probability of atypical pneumonia based on clinical symptoms and signs like fever, cough, dyspnoea, headache. Crepitations and presence of new pulmonary infiltrates on chest $x$-ray, in cases like COPD with acute exacerbation, bronchial asthma with acute exacerbation and community-acquired pneumonia cases. 90 blood samples collected were subjected to ELISA to detect IgM antibody (EUROIMMUN) for Chlamydia pneumoniae, Legionella pneumophila, and Mycoplasma pneumoniae was performed according to manufacturer's instructions.

\section{EUROIMMUN Recommends Interpreting Results as follows-}

Ratio: $<0.8$ negative.

Ratio: $\mathrm{R}>0.8$ to 1.1 borderline.

Ratio: $>1.1$ positive.

\section{Sputum Collection}

Sputum samples were collected in 2 containers before the patient was started on antibodies.

Aerosol-induced sputum collected by allowing the patient to breathe aerosolised droplets, using an ultrasonic nebuliser containing $0.85 \% \mathrm{NaCl}$ or until a strong cough reflex is initiated. Sputum is collected from the patients in separate sterile container under aseptic conditions and transported to laboratory immediately for macroscopic examination, Gram stain and culture sensitivity. The samples which are showing no pathogenic organisms (NPO) were subjected to PCR for amplification of V3 region of 16 SMA followed by Sanger sequencing.

\section{RESULTS}

90 patients were included in the study.

\begin{tabular}{|c|c|}
\hline Sample & No \\
\hline Sputum & 90 \\
\hline Serum & 90 \\
\hline \multicolumn{2}{|c|}{ Table 1. Total Samples Collected $(\mathbf{n}=90)$} \\
\hline
\end{tabular}

\begin{tabular}{|c|c|c|}
\hline Age & No & \% \\
\hline $16-26$ & 12 & 13.3 \\
\hline $27-36$ & 14 & 15.5 \\
\hline $37-46$ & 4 & 4.4 \\
\hline $47-56$ & 26 & 28.8 \\
\hline $57-66$ & 10 & $11.1 \%$ \\
\hline $67-76$ & 4 & $4.4 \%$ \\
\hline Table 2. Age Wise Distribution of Cases (n=90) \\
\hline
\end{tabular}

\begin{tabular}{|c|c|c|}
\hline Sex & No & \% \\
\hline Males & 59 & 59 \\
\hline Females & 31 & 31 \\
\hline \multicolumn{2}{|c|}{ Table 3. Sex Wise Distribution of Cases (n=90) } \\
\hline
\end{tabular}

\begin{tabular}{|c|c|c|}
\hline Patients & No & \% \\
\hline Outpatients & 54 & 48.6 \\
\hline In Patients & 36 & 40 \\
\hline \multicolumn{2}{|c|}{ Table 4. Outpatient Inpatient Ratio (n=90) } \\
\hline
\end{tabular}




\begin{tabular}{|c|c|c|}
\hline Symptom & No & \% \\
\hline Cough & 80 & 88.8 \\
\hline Fever & 65 & 72.2 \\
\hline Chest Pain & 18 & 20 \\
\hline Dyspnoea & 42 & 46.6 \\
\hline Headache & 8 & 8.8 \\
\hline \multicolumn{2}{|c|}{ Table 5. Common Symptoms (n=90) } \\
\hline
\end{tabular}

\begin{tabular}{|c|c|c|}
\hline Pathogen & No & \% \\
\hline Chlamydia pneumoniae & 2 & $2.2 \%$ \\
\hline Mycoplasma pneumoniae & 4 & $4.4 \%$ \\
\hline Legionella pneumophila & 11 & $12.2 \%$ \\
\hline \multicolumn{2}{|r|}{ Table 6. IgM Antibodies Detection } \\
of Atypical Pathogens by ELISA (n=90)
\end{tabular}

\begin{tabular}{|c|c|c|}
\hline Pathogen & No & \% \\
\hline Chlamydia pneumoniae & 1 & $1.1 \%$ \\
\hline Mycoplasma pneumoniae & 2 & $2.2 \%$ \\
\hline Legionella pneumophila & 5 & $5.5 \%$ \\
\hline \multicolumn{2}{|c|}{$\begin{array}{c}\text { Table 7. Detection of Atypical Pathogens } \\
\text { by Sanger Sequencing (n=90) }\end{array}$} \\
\hline
\end{tabular}

\begin{tabular}{|c|c|c|}
\hline Pathogen & No & \% \\
\hline Streptococcus spp. & 20 & 22.2 \\
\hline Streptococcus pneumoniae & 16 & 17.7 \\
\hline Pseudomonas aeruginosa & 8 & 8.8 \\
\hline Stenotrophomonas maltophilia & 4 & 44 \\
\hline Prevotella spp. & 2 & 2.2 \\
\hline Chryseobacterium spp. & 2 & 2.2 \\
\hline Uncultured bacteria & 30 & 33.3 \\
\hline $\begin{array}{r}\text { Table 8. Other Bacteria Detected } \\
\text { by Sanger Sequencing (n=90) }\end{array}$ \\
\hline
\end{tabular}

\section{DISCUSSION}

The study includes 90 samples of sputum and serum from each patient. Among the 90 samples collected, 31 were female patients, 59 were male patients. A slight male preponderance was seen in the present study. According to a study by Maria A. Marwetinez et al, 2008, Chile,12 there were 192 (53.8\%) males and 165 (46.2\%) females.

The patients' age ranged from 18 to 94 years (median 63 years). The patients included in our study group ranged from 17-76 years. The most commonly affected age group was 4766 years followed by 27-36 years. Seroprevalence was detected by IgM antibody test using ELISA (EUROIMMUN) microplate wells coated with antigens (Detergent extract of Mycoplasma pneumoniae, strain MAC ATCC 15531, MOMP of CWl-029 strain of Chlamydia pneumoniae, LPS Legionella pneumophila strain 1-7) for IgM detection of Mycoplasma pneumoniae, Chlamydia pneumoniae and Legionella pneumophila. Out of 90 serum samples, 17 samples positive for IgM antibodies for atypical bacteria identified by ELISA Mycoplasma pneumoniae 4 (4.4\%), Chlamydia pneumoniae 2 (2.2\%), Legionella pneumophila $11(12.2 \%)$.

According to a study by Levent Erkan et al 2008,13 pathogens most commonly demonstrated in COPD were: Haemophilus influenzae (30\%), Chlamydophila pneumoniae (17\%), and Mycoplasma pneumoniae (9\%).

Out of 17 positive cases, $12(70.5 \%)$ were male subjects and $5(29.4 \%)$ were female subjects. The present study detected IgM antibodies for Mycoplasma pneumoniae in 4.4\% patients.

Two other recent studies have found C. pneumoniae to be associated with exacerbations in 24\% (Mogulkoc et al 1999; Karnak et al 2001).

\begin{tabular}{|c|c|c|c|}
\hline Author & Place & Year & $\begin{array}{c}\text { Mycoplasma } \\
\text { pneumoniae \% }\end{array}$ \\
\hline Seungioon et al ${ }^{14}$ & Korea & 2002 & 8.6 \\
\hline Bansal S et al $15^{16}$ & India & 2004 & 15 \\
\hline Oberola et al $^{16}$ & India & 2006 & 16.5 \\
\hline Youninglui et al $^{17}$ & China & 2010 & 20.7 \\
\hline EI sayedzaki M18 $^{18}$ & Egypt & 2009 & 5 \\
\hline Fang Chingliu et al $^{1}$ Japan & 2008 & $3.7 \%$ \\
\hline Ramachaudary et al ${ }^{11}$ & India & 2013 & 4.47 \\
\hline Present study & India & 2015 & $4.4 \%$ \\
\hline \multicolumn{4}{|c|}{ Table 9. Studies showing Detection of } \\
Mycoplasma pneumoniae IgM Antibodies \\
\hline
\end{tabular}

According to a study by Rama Chaudhry et al, 2013, India, ${ }^{11}$ IgM antibodies for Mycoplasma pneumoniae were detected in $4.47 \%$ of patients of Community-acquired pneumonia.

In 2004, 3.7\% cases of Community-Acquired Pneumonia were detected due to Mycoplasma pneumoniae and 2.9\% in year 2005, this was seen in adult population.

Present study shows similarity in prevalence when compared to these two studies. In the present study, IgM antibodies for M. pneumoniae have been noted in 2 cases of CAP and 2 cases of bronchial asthma with acute exacerbations.

Blasi et al, 2004, Europe reported a role for C. pneumoniae and M. pneumoniae infection as a trigger for 5$30 \%$ episodes of wheezing or acute asthma exacerbation. ${ }^{20}$

Paraskevi Xepapadaki et al, $2008^{21}$ found that $\mathrm{M}$. pneumoniae were associated with hospitalisation for asthma exacerbation in $18 \%$.

Rama Chaudhry et $\mathrm{al}^{11}$ found that males are more commonly affected than females, male to female ratio in 6:1.

The present study showed 4 cases positive for $M$. pneumoniae of which 3 (75\%) cases were male and 1 (25\%) female.

In our study, the patients presenting with cough were 80 (88.8\%), fever 65 (72.2\%), dyspnoea 42 (46.6\%).

Rama Chaudary et al 2013 found that ${ }^{11}$ most common clinical symptoms are cough (91\%), fever (74.5\%), dyspnoea (63\%), diarrhoea 19\%.

Our study detected IgM antibodies for Legionella pneumophila in $12.2 \%$ of patients. S Ewing et al, $2002^{22,23}$ study in Europe on a large population, hospitalised with acute exacerbation of COPD, provides evidence for the first time for Legionella spp. infection as a potential underlying pathogen in as many as $16.7 \%$ of cases detected by serology.

\begin{tabular}{|c|c|c|c|}
\hline Author & Place & Year & $\begin{array}{c}\text { Mycoplasma } \\
\text { pneumoniae \% }\end{array}$ \\
\hline Almudenarojas et al 24 & Spain & 2005 & 29.7 \\
\hline Sabah Javed et al 25 & India & 2010 & 15.92 \\
\hline Present study & India & 2015 & 12.2 \\
\hline
\end{tabular}


According to a study by Sabah Javed et al, 2010,26 IgM antibodies for Legionella pneumophila were detected in $15.92 \%$ of cases. Most common presenting symptoms are fever $80.6 \%$, cough $96.7 \%$, dyspnoea $58 \%$, headache $16.1 \%$ our study showed fever (76.6\%) 69 cases, cough (87.7\%) 72 cases, dyspnoea (38.8\%)35 cases, headache (8.8\%) 8 cases.

Almudenarojas et al, $2005^{27}$ reported $29.7 \%$ positive for IgM L. pneumophila and that most cases are caused by serogroup-1.

In this study, ELISA kit that has been used contained antigen of Legionella pneumophila serogroup 1-7. Hence in cases detected by this method, disease could be caused by any of these serogroups, further correlation has been attempted with Sanger sequencing.

Direct method of diagnosis include culturing, direct fluorescent staining, and antigen detection in urine. While the first two methods display low and variable sensitivities, the latter has become a reference technique in most laboratories, enabling easy and early diagnosis of legionellosis. Indirect immune fluorescence is the most common method for serological diagnosis although serology yields good sensitivity and specificity data. The enzyme-linked immunosorbent assay (ELISA) technique generally shows higher sensitivity and better characteristics in terms of both automation and objective measurement than immunofluorescence.

In a study by Lt. Col. Dr. Agarwal et al, 2008, India Chlamydia pneumoniae has been discussed as a possible cofactor causing chronic obstructive pulmonary disease (COPD) and asthma. They detected IgM antibodies for Chlamydia pneumoniae in $18.3 \%$ of patients. In contrast to above study, our study detected only $2.2 \%$ of Chlamydia pneumoniae by ELISA.

According to Miyashita N et al, 1998 and Gencay M et al, $2001,28,29$ the rate of $3 \%$ compares favourably to serological studies of Chlamydia pneumoniae in COPD and asthma.

\begin{tabular}{|c|c|c|c|}
\hline Author & Place & Year & $\mathbf{\%}$ \\
\hline N Sopena et al $^{28}$ & Spain & 1999 & 13.5 \\
\hline WS Lim et al $^{29}$ & UK & 2001 & 13 \\
\hline Oberoi A et al $^{16}$ & India & 2006 & 17.6 \\
\hline Youninglui et al $^{17}$ & China & 2010 & 6.6 \\
\hline Present & India & 2011 & 2.2 \\
\hline $\begin{array}{c}\text { Table 11. Studies showing detection of Chlamydia } \\
\text { pneumoniae IgM antibodies }\end{array}$ \\
\hline
\end{tabular}

According to a study by J. Nagesh, 2004, UK, ${ }^{30}$ found that Serological testing is considered the most useful means of determining the prevalence of C. pneumoniae infection. MIF is currently the standard in C. pneumoniae Serology, but is subjective and requires an expert microscopist to interpret the result. Inter-laboratory variation of MIF shows an overall agreement with reference standard titres of c.80\%. ELISA is more objective, can be automated. ELISA is therefore easier to standardise and is the preferred diagnostic method. ELISA may become a preferred objective test in the seroepidemiological study of C. pneumoniae infection and its link with atherosclerotic vascular disease.

According to a study by Surinder Kumar et al, 2011,31 India, tachypnoea was documented in 9 (75\%) cases; cough and coryza in $12(100 \%)$ cases; fever in $8(66.67 \%)$, while 4 $(33.33 \%)$ cases were afebrile.
Five (41.67\%) cases documented audible/auscultable wheezing and 3 (25\%) crepitations. The presence of C. pneumoniae antibody was higher in males [10 (7.87\%)] males than in females [2 (2.74\%)].

Our study detected Chlamydia pneumoniae antibodies in 2 male patients and none in the female patients.

Urinary antigen detection has been treated as the most specific reference test for diagnosis of legionellosis, but expensive.

In view of these facts further correlation has been attempted with help of Sanger sequencing to establish diagnosis and to compare sensitivity and specificity due to the following reasons-

1. IgM antibodies to the three organisms appear in 2 week in most cases.

2. IgM antibodies cross react with other gram negative bacteria.

Hence in order to diagnose atypical pneumonia is acute stage IgM detection could be unreliable.

Above lines correlated with the study conducted by $\mathrm{M}$ Socan al ${ }^{21} 1999$ - In our study cases have been selected based on high suspicion of atypical pneumonia and patients showing positive IgM for atypical bacteria were treated with macrolides to which they responded and showed clearing of lung fields in follow up therefore clinical correlation helped to clinch clinical diagnosis and proved IgM detection as a useful tool in diagnosis. All patients received Tab Azithromycin for a period of seven days and had good recovery of symptoms.

Out of 90 sputum samples, 8 samples were positive for atypical bacteria by Sanger sequencing (PCR of 16S rRNA followed by sequencing)- Mycoplasma pneumoniae 2 (2.2\%), Chlamydia pneumoniae $1(1.1 \%)$ Legionella pneumophila 5 (5.4\%).

Maria A. Martinez et al 2008 detected M. pneumoniae in $6.4 \%$ of patients by PCR (targeting $16 \mathrm{~S}$ rRNA gene) study by charlotte Gaydos et al 1992 showed Chlamydia pneumoniae positive in $5.1 \%$ of patients by PCR (targeting 16S rRNA gene).

Tsutomu Yamazaki et al 2006 Japan $^{32}$ detected 19.5\% of Chlamydia pneumoniae cases positive by PCR.

A study by Bernard la Scola et al 1997 France 33 found polymerase chain reaction (PCR) analysis with use of $16 \mathrm{~S}$ rRNA gene primers with a broad specificity detected bacterial DNA in pus samples. Subsequent nucleotide base determination of the amplified DNA demonstrated that the detected DNA was derived from Mycoplasma pneumoniae. When the sequence was aligned and compared with $16 \mathrm{~S}$ rRNA gene sequences available in GenBank, it demonstrated a $100 \%$ similarity to the $16 \mathrm{~S}$ rRNA gene sequence.

In a M.W. Carter et al 1991 UK Computer taxonomic study, using the nucleotide and inferred amino acid sequence of the MOMP of C. pneumoniae IOL-207 and all known chlamydia MOMP sequences supported the designation of $\mathrm{C}$. pneumoniae as a new species. Comparative studies of the nucleotide sequences of key C. pneumoniae antigens with other Chlamydia species showed that there was $67.2-67.9 \%$ homology between the C. pneumoniae MOMP nucleotide sequence and C. trachomatis sequences and 71.5-72.4\% homology with the C. psittaci sequences. 
A study by Bertil Pettersson et al 1997 Atlanta $^{34}$ found that comparison of RNA sequences of the ribosomal small subunit (16S) has proved very useful. Pneumonia strains and 4 C. pecorum strains were obtained by semiautomated solidphase DNA sequencing.

In a study by J.L Cloud et al 2000,35 the Legionella-specific PCR assay, the 16S rRNA gene was very sensitive, (100\%). Their studies indicate that sequencing of all PCR-positive samples for confirmation of results provide a higher degree of specificity without a loss of sensitivity.

According to a study by M. Socan et al 1999,36 selection of 16S rRNA gene sequence harbours many advantages. A large database of $16 \mathrm{~S}$ rRNA genes is available, facilitating selection of appropriate sequences, large amplification products are generated that can easily be identified by agarose gel electrophoresis even after digestion with restriction endonucleases.

A pilot study conducted by Sandra Reuter et $\mathrm{al}^{37}$ demonstrates the feasibility of using rapid whole genome sequencing (WGS) to discriminate outbreak from nonoutbreak isolates of L. pneumophila compared with uncut typing method. It also provides high degree of discrimination for management of other bacteria such as MRSA, Klebsiella.

A study by Kwok-Huggchan et al ${ }^{38}$ compared two sequencing methods to assess macrolide resistant Mycoplasma pneumoniae mutant genotypes and showed that pyrosequencing and Sanger sequencing can identify mutations.

A comparative genome analysis of M. Pneumoniae was done by Lixao et $\mathrm{al}^{39}$ in their study by using whole genome sequencing, which showed that all 15 strains show high degree of sequencing similarity ( $>99 \%$ ).

Taking above studies in to consideration, present study has adopted Sanger sequencing in identifying and discriminating a range of bacteria in seroprevalence samples taken from patients suspected of suffering from atypical pneumonia, although this study has been designed to identify and report prevalence of the 3 organisms L pneumonia, M. Pneumoniae and C. Pneumoniae; 16S rRNA has been targeted by Sanger sequencing in order to identify other bacteria implicated in atypical pneumonia.

Sanger sequencing in available data has been employed mainly as a research tool to identify strains in Legionella spp., Mycoplasma spp., Chlamydia species and has reported as highly specific.

Low sensitivity of Sanger sequencing in comparison with IgM detection could be due to low bacterial load at the time of collection of the samples. As a result, this method has identified the predominant bacteria in the samples.

\section{SUMMARY AND CONCLUSION}

- Out of 90 serum samples, 17 cases were positive for IgM antibodies for atypical bacteria.

- Out of 90 sputum samples, 8 cases were positive by Sanger sequencing.

- The common presenting symptoms were cough, fever, chest pain, dyspnoea and headache.

- More number of cases were detected in Communityacquired pneumonia patients followed by COPD and bronchial asthma with acute exacerbations.

- Atypical bacterial pneumonias presenting as Community-acquired pneumonia need specific diagnosis and respond better to Macrolide antibiotics.
Serological diagnosis correlated with clinical symptoms \& signs using IgM ELISA (EUROIMMUN) and has been found to be more sensitive (74\%) for three organisms.

Cases from which samples showed IgM negative clinically proved to be atypical pneumonia since they were treated with macrolides discharged and on followup showed resolution of lung fields in $\mathrm{x}$-ray. IgM ELISA in serum has been found to be more sensitive than Sanger sequencing in sputum samples. The reasons being low bacterial load at the time of collection which might have resulted in missing the $16 \mathrm{~S}$ rRNA of the pathogens in question. The uncultured bacteria reported in Sanger sequencing might have potential in being implicated in aetiology of atypical pneumonia is $30 \%$. We here by conclude that IgM ELISA having correlated clinically with reasonable sensitivity could be a useful tool in diagnosing atypical pneumonia caused by L. pneumophila.

M. pneumoniae and C pneumoniae Sanger sequencing in comparisons of low sensitivity although highly specific can be recommended for application in discriminating species and not for diagnosis from sputum samples.

We further conclude that clinicoradiological diagnosis supported by IgM ELISA is a reliable tool in identifying cases of atypical pneumonia caused by the three organisms $\mathrm{L}$ pneumonia, M. Pneumoniae and C. Pneumoniae.

\section{REFERENCES}

[1] Green DS, Pedro SGS. Empiric therapy of communityacquired pneumonia. Semin Respir Infect 2000;15(3):227-33.

[2] Cunha BA. The atypical pneumonias: clinical diagnosis and importance. CMI 2006;12(3):12-24.

[3] Qasem JA, Khan ZU, Shiji G, et al. Polymerase chain reaction as a sensitive and rapid method for specific detection of Mycoplasma pneumoniae in clinical samples. Microbiol Res 2002;157(2):77-82.

[4] Thibodeau KP, Viera AJ. Atypical pathogens and challenges in community-acquired pneumonia. Am Fam Physician 2004;69(7):1699-706.

[5] Yzerman PF, DenBoer JW, Lettinga KD, et al. Sensitivity of three serum antibody tests in a large outbreak of Legionnaire's disease in the Netherlands. Journal of Medical Microbiology 2006;55:561-6.

[6] Yong SFY, Tan SH, Wee J, et al. Molecular detection of legionella: moving on from MIP. Front Microbiol 2010;1:123.

[7] Oktem IM, Ellidokuz H, Sevinc C, et al. PCR and serology were effective for identifying Chlamydophila pneumoniae in a lower respiratory infection outbreak among military recruits. Jpn J Infect Dis 2007;60(23):97-101.

[8] Min-Chul Cho, Kim H, An D, et al. Comparison of sputum and nasopharyngeal swab specimens for molecular diagnosis of Mycoplasma pneumoniae, Chlamydophila pneumoniae, and legionella pneumophila. Ann Lab Med 2012;32(2):133-8.

[9] Coscolla M, Gonza'lez-Candelas F. Direct sequencing of legionella pneumophila from respiratory samples for sequence-based typing analysis. Journal of Clinical Microbiol 2009;47(9):2901-5. 
[10] Diederen BMW, Kluytmans JAJW, VandenbrouckeGrauls CM, et al. Utility of real-time PCR for diagnosis of legionnaires disease in routine clinical practice. Journal of Clinical Microbiol 2008;46(2):671-7.

[11] Chaudhry R, Sharma S, Javed S, et al. Molecular detection of Mycoplasma pneumoniae by quantitative real-time PCR in patients with Community-acquired pneumonia. India J Med Res 2013;138(2):244-51.

[12] Martínez MA, Ruiz M, Zunino E, et al. Detection of Mycoplasma pneumoniae in adult communityacquired pneumonia by PCR and serology. Journal of medical microbiology 2008;57(Pt 12):1491-5.

[13] Erkan L, Uzun 0, Findik S, et al. Role of Bacteria in acute exacerbations of chronic obstructive pulmonary disease. International Journal of COPD 2008;3(3):4637.

[14] Lee SJ, Lee MG, Jeon SK, et al. Atypical pathogens in adult patients with Community-acquired pneumonia in Korea. Jpn J Infect Dis 2002;55(5):157-9.

[15] Bansal S, Kashyap S, Pal LS, et al. Clinical and bacteriological profile of Community-acquired pneumonia in Shimla, Himachal Pradesh. Indian J Chest Dis Allied Sci 2004;46(1):17-22.

[16] Aroma 0, Agarwal A. Bacteriological profile, serology and antibiotic sensitivity pattern of micro-organisms from Community-acquired pneumonia. JK science 2006;8(2):79-82.

[17] Youningb L, Chen $M$, Zhao T, et al. Causative agent distribution and antibiotic therapy assessment among adult patients with Community-acquired pneumonia in Chinese urban population. BMC infectious diseases 2009;9:31.

[18] El Zaki SM, Goda T. Clinico-pathological study of atypical pathogens in community-acquired pneumonia: a prospective study. J Infect Dis 2009;3(3):199-205.

[19] $\mathrm{Qu} \mathrm{J}$, Cao B. Research progress in atypical pathogens of Community-acquired pneumonia. Community Acquired Infection 2014;1(1):11-4.

[20] Blasi F. Atypical pathogens and respiratory tract infections. Eur Respir J 2004;24(1):171-81.

[21] Xepapadaki P, Koutsoumpari L, Papaevagelou V, et al. Atypical bacteria and macrolides in asthma. Allergy, Asthma, and Clinical Immunology 2008;4(3):111-6.

[22] Ewig S. Legionella spp. In acute exacerbation of chronic obstructive pulmonary disease: what is the evidence? Eur Respir J 2002;19:387-9.

[23] Lieberman D, Lieberman D, Shmarkov O, et al. Serological evidence of legionella species infection in acute exacerbation of COPD. Eur Respir J 2002;19(3):392-7.

[24] Young UH, Hong JH, Oh KJ, et al. Macrolide resistance of Mycoplasma pneumoniae and its detection rate by real-time PCR in primary and tertiary care hospitals. Ann Lab Med 2013;33(6):410-4.

[25] Liu FC, Chen PY, Huang FL, et al. Do serological tests provide adequate rapid diagnosis of Mycoplasma pneumoniae infection? Japanese Journal of Infectious Diseases 2008;61(5):397-9.
[26] Miyashita N, Niki Y, Nakajima M, et al. Chlamydia pneumoniae infection in patients with diffuse panbronchiolitis and COPD. Chest 1998;114(4):96971.

[27] Gencay M, Rudiger JJ, Tamm M, et al. Increased frequency of Chlamydia pneumoniae antibodies in patients with asthma. Am J Respir Crit Care Med 2001;163(5):1097-100.

[28] Sopena N, Sabera M, Botet PML, et al. Prospective study of Community-acquired pneumonia of bacterial etiology in adults. Eur J Clinical microbial infect Dis 1999;18(12):852-8.

[29] Lim WS, Macfarlane JT, Boswell TC, et al. Study of Community-acquired pneumonia aetiology in adults admitted to hospital: implications for management guidelines. Thorax 2001;56(4):296-301.

[30] Ngeh J, Gupta S, Goodbourn C. The reproducibility of an enzyme-linked immune sorbent assay for detection of Chlamydia pneumoniae-specific antibodies. Clin Microbiol Infect 2004;10(2):171-4.

[31] Diederen BM, de Jong CM, Marmouk F, et al. Evaluation of real-time PCR for the early detection of legionella pneumophila DNA in serum samples. Journal of Medical Microbiology 2007;56(Pt 1):94-101.

[32] She RC, Thurber A, Hymas WC, et al. Limited utility of culture for Mycoplasma pneumoniae and Chlamydophila pneumonia for diagnosis of respiratory tract infections. Journal of Clinical Microbiology 2010;48(9):3380-2.

[33] LaScola B, Michel G, Raoult D. Use of amplification and sequencing of the 16S rRNA gene to diagnose Mycoplasma pneumoniae osteomyelitis in a patient with hypogammaglobulinemia. Clinical Infection Diseases 1997;24:1161-3.

[34] Pettersson B, Anderson A, Leitner T, et al. Evolutionary relationship among members of the genus chlamydia based on 16S ribosomal DNA analysis. Journal of bacteriology 1997;179(13):4195-205.

[35] Cloud JL, Corroll KC, Pixton P, et al. Detection of Legionella species in respiratory specimens using PCR with sequencing confirmation. JCM 2000;38(5):170912.

[36] Socan M, Marinic-Fiser N, Kese D. Comparison of serological test with urinary antigen detection for diagnosis of Legionnaires' disease in patients with community-acquire pneumonia. Clinical Microbiol Infect 1999;5(4):202-4.

[37] Reuter S, Harrison TG, Koser CU, et al. A pilot study of rapid whole-genome sequencing for the investigation of a legionella outbreak. BMJ Open 2013;3(1):e002175.

[38] Kwok-Hung Chan, Kelvin KW, Betsy WKC, et al. Comparison of pyrosequencing, Sanger sequencing, and melting curve analysis for detection of lowfrequency macrolide-resistant Mycoplasma pneumoniae quasi species in respiratory specimens. Journal of Clinical Microbiology 2013;51(8):2592-8.

[39] Xiao L, Ptacek T, Osborne JD, et al. Comparative genome analysis of Mycoplasma pneumoniae. BMC Genomics 2015;16:610. 